\title{
REVIEW
}

\section{Fatigue in cholestatic liver disease-a perplexing symptom}

\section{Kumar, R K Tandon}

Postgrad Med J 2002;78:404-407

Fatigue is an important symptom and a quality of life determinant in patients with cholestatic liver disease. The pathogenesis of fatigue is obscure, although alterations in central neurotransmission and peripheral muscle dysfunction have been incriminated. No effective treatment is available at present. The available literature on fatigue in cholestatic liver disease is reviewed.

See end of article for authors' affiliations

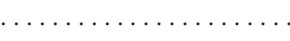

Correspondence to: Professor Rakesh K Tandon, Department of Gastroenterology, All India Institute of Medical Sciences, New Delhi, India; rakesh_tandon@ hotmail.com

Submitted 29 August 2001 Accepted 7 May 2002

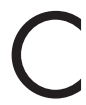
holestatic liver disease typically presents with pruritus, steatorrhoea, deficiency of $\checkmark$ fat soluble vitamins, and metabolic bone disease. In recent years, fatigue has been recognised as a significant symptom in this group of diseases. $^{1{ }^{2}}$ It remained neglected, until recently, because of its non-specific nature and lack of objective assessment techniques. Its pathogenesis and effective therapy, however, still remain elusive. Fatigue is a complex symptom, defined as a persistent sense of exhaustion, inability to perform usual routine work, and a decreased capacity for physical and mental work. ${ }^{3}$ Understanding the basis of this symptom has become more important now because many patients with primary biliary cirrhosis (PBC) are being diagnosed early in the natural course of this slowly progressive disease. ${ }^{4}$ Furthermore, ursodeoxycholic acid (UDCA) treatment has reduced the progression of the disease as suggested by many long term follow up studies, ${ }^{5-8}$ although one recent meta-analysis did not find any survival benefit with UDCA. ${ }^{9}$ In the absence of cholestatic symptoms and liver failure, fatigue is being considered as one of the most debilitating symptoms of cholestatic liver disease, adversely affecting the quality of life. ${ }^{12}$ In the present article, we review the available literature on fatigue in cholestatic liver disease.

\section{PREVALENCE OF FATIGUE, ASSESSMENT,} AND IMPACT ON QUALITY OF LIFE

Fatigue was present in $81 \%$ of patients and was the most prevalent symptom in the Canadian demography study of PBC. ${ }^{1}$ Various clinical trials of $\mathrm{PBC}$ have shown that fatigue is present in $60 \%-76 \%$ of patients at entry into the trials. ${ }^{11-13}$ Recent reports, specifically addressing fatigue, have reported it to be present in $68 \%-85 \%$ of patients with $\mathrm{PBC}^{2}{ }^{10}$ It is almost equally prevalent among patients with primary sclerosing cholangitis and drug induced cholestasis. ${ }^{114} 15$ Half of the patients with fatigue consider it to be their worst or one of the worst symptoms, underscoring the importance of understanding this symptom. ${ }^{10}$
Most therapeutic trials of PBC have measured fatigue as a subjective symptom and reported it as either present or absent. Recognition of fatigue as an important symptom in PBC stimulated the search for an objective method to assess and measure it. Cauch-Dudek et $a l^{2}$ measured fatigue as self rated fatigue severity score (FSS) using the fatigue assessment instrument. ${ }^{16}$ This measures both qualitative and quantitative aspects of fatigue. FSSs were significantly higher in patients having verbally reported fatigue as compared with those having no verbally reported fatigue.

The Fisk fatigue severity score (FFSS), originally developed to assess the impact of chronic fatigue syndrome on quality of life, ${ }^{17}$ has also been recently validated in patients with $\mathrm{PBC}$ to assess fatigue and its effect on quality of life. ${ }^{10}{ }^{18}$ This tool consists of a questionnaire that scores the effect of fatigue on 40 aspects of day-to-day life. These aspects broadly pertain to psychosocial, cognitive, and physical activity. The FFSS was reproducible both at short and long intervals indicating its reliability in assessing fatigue. Median FFSS was found to be 2.3 times higher in patients with PBC than in chronic disease controls. ${ }^{18}$ A similar degree of fatigue was also found in patients with primary sclerosing cholangitis. ${ }^{10}$

The Canadian demography study of PBC concluded that fatigue interfered with physical activity, family life, and job performance in $73 \%$, $57 \%$, and $30 \%$ of patients, respectively. ${ }^{1}$ The quality of sleep ( subjective sleep quality, habitual sleep efficiency, sleep disturbance, daytime dysfunction) was poor in the fatigued patients, though the duration of sleep was similar in fatigued and non-fatigued patients and in normal subjects. ${ }^{2}$ The poor quality of sleep could not be explained by pruritus, as $57 \%$ of patients with fatigue had no pruritus. Depression was present in $45 \%$ of patients with PBC. ${ }^{10}$ Further, $71 \%$ of fatigued patients had depressive symptoms as compared with $18 \%$ of non-fatigued patients. ${ }^{2}$ More patients with fatigue had moderate or severe depression compared with those without. Fatigue, sleep disturbance, and depression often coexist in patients with PBC, but it remains to be determined whether fatigue induces sleep disturbance and/or depression or vice versa. Their inter-relationship is complex and needs further elucidation.

Abbreviations: FSS, fatigue severity score; FFSS, Fisk fatigue severity score; $5 \mathrm{HT}$, 5-hydroxytryptamine; IL-1, interleukin-1; PBC, primary biliary cirrhosis; UDCA, ursodeoxycholic acid 


\section{Box 1: Pathogenesis of fatigue}

- Alteration in hypothalamo-pituitary-axis, diminished corticotrophin releasing hormone stores and release.

- Altered serotoninergic neurotransmission.

- Abnormality of cytokine release particularly interleukin-1.

- Decreased hypothalamic nitric oxide formation.

- Peripheral muscle dysfunction.

\section{PATHOGENESIS OF FATIGUE IN CHOLESTATIC LIVER DISEASE}

The pathogenesis of fatigue is poorly understood. It is important to elucidate its pathogenesis to develop appropriate treatment. Fatigue constitutes a part of non-specific symptoms such as malaise, lethargy, anorexia, listlessness, loss of social interest and inability to concentrate, which are commonly associated with a number of disease states. These symptoms have been termed as sickness behaviours and are felt to be secondary to the disease process. ${ }^{19}{ }^{20}$ However, in cholestatic liver disease fatigue is a major symptom and is at times the presenting symptom. Patients with PBC have a higher FFSS compared with other hospital-attending patients with chronic disease, signifying that fatigue is a specific symptom related to PBC. ${ }^{18}$ The severity of fatigue, however, does not correlate with markers of liver disease severity like histological grades, age, serum albumin, bilirubin, prothrombin time, and aminopyrine breath test, indicating that the pathogenesis of fatigue is independent of the severity of liver disease. ${ }^{210}{ }^{18}$ This has led to a suggestion that fatigue may be an extrahepatic association of cholestatic liver disease just like other associated autoimmune diseases. ${ }^{10}$

Sickness behaviours are a part of a specific, organised response to environmental insults (for example, infection or inflammation) and other stressful conditions. ${ }^{19} 20$ Alterations in the hypothalamus-pituitary-adrenal axis are known to modulate behavioural changes occurring during stressful conditions. ${ }^{21}{ }^{22}$ Altered central neurotransmission appears to play a part in the generation of fatigue associated with many disease states, ${ }^{23}{ }^{24}$ and has also been implicated in the pathogenesis of pruritus in cholestatic liver disease. 25 Recently, cytokines have also been implicated in the pathogenesis of sickness behaviours. ${ }^{27-29}$ Working on these clues Swain and colleagues have performed a series of elegant experiments on bile duct resected rats, as a model of cholestasis, to elucidate the pathogenesis of fatigue in cholestatic liver disease. $^{30-33}$ These experiments support the theory that fatigue in PBC is central in origin. The validity of these experiments in human disease states, however, has not been tested. There is evidence that peripheral muscle dysfunction may also contribute to the pathogenesis of fatigue in PBC. ${ }^{34}$

\section{(1) Alteration in the hypothalamus-pituitary-adrenal \\ axis}

In first of these experiments bile duct resected rats entered fewer inner squares of an open field apparatus and produced fewer faecal boluses than the control (sham resected) rats. ${ }^{31}$ Placing a rat in an open field is a stressful stimulus for the animal and exploration of inner versus outer squares in an open field can be affected by a number of factors, specifically a defective release of central corticotrophin releasing hormone. ${ }^{35-37}$ Diminished faecal bolus production during stress is also consistent with diminished central corticotrophin releasing hormone release. ${ }^{38}$ The altered hypothalamus-pituitary-adrenal axis response was further confirmed by finding a low rise in plasma adrenocorticotrophic hormone on exposure to the stress of open space in bile duct resected rats. ${ }^{31}$ Thus, an abnormal pattern of behaviour and altered function of the hypothalamus-pituitaryadrenal axis coexist in rats with cholestasis, though a causal relationship between the two has not been established.

\section{(2) Altered serotoninergic neurotransmission}

There is evidence to show that fatigue is associated with an altered serotoninergic neurotransmission. Fatigued rats during prolonged exercise have raised levels of brain 5-hydroxytryptamine (5HT) and treatment with a $5 \mathrm{HT}_{2}$ antagonist prolonged the exercise period, whereas treatment with a 5HT agonist shortened the exercise period. ${ }^{39}$ Serotonin reuptake inhibitor (paroxetine), that acts as a serotonin agonist centrally, does indeed decrease exercise tolerance in male athletes. ${ }^{40}$ Altered serotoninergic neurotransmission has also been implicated in the pathogenesis of fatigue in diseased states like chronic fatigue syndrome and postviral fatigue..$^{23}$ Further, altered serotoninergic neurotransmission is known to exist in cholestatic states-as has been suggested by the reversal of pruritus on administration of ondansetron, a $5 \mathrm{HT}_{3}$ receptor antagonist. ${ }^{41}$

In a rat model of fatigue assessment, using a swim test, Swain and Maric demonstrated that bile duct resected rats (cholestatic rats) had significantly reduced activity scores compared with carbon tetrachloride treated rats (rat model for hepatitis) and sham resected rats (non-cholestatic controls). ${ }^{32}$ Administration of a serotonin $\left(5 \mathrm{HT}_{1 \mathrm{~A}}\right)$ receptor agonist reversed and improved activity scores in bile duct resected rats, implicating altered serotoninergic neurotransmission in the pathogenesis of fatigue in cholestatic states. ${ }^{32}$

\section{(3) Cytokines}

Cytokines have also been implicated in the pathogenesis of sickness behaviours. ${ }^{19} 2728$ Interleukin-1 (IL-1) induces sickness behaviours in rats ${ }^{42-44}$ and central infusion of IL-lra, a specific IL-1 receptor antagonist, reverses this. ${ }^{29}$ In bile duct resected rats central infusion of IL-1 produced a marked reduction in locomotor activity, while in the control rats the same dose of IL-1 had an insignificant effect. ${ }^{45}$ The anorectic response to the central IL- 1 infusion was, however, similar in cholestatic and non-cholestatic rats. Thus, cholestasis is characterised by augmented central responsiveness to IL- 1 with respect to a decrease in locomotor activity only. IL-1 expression is enhanced in brain in response to peripheral stimuli (endotoxin administration) and stress. ${ }^{46-48}$ Hence during inflammation or stressful conditions in cholestatic patients IL-1 may contribute to the fatigue. Mechanisms underlying the enhanced sensitivity of cholestatic rats to IL-1 induced decrease in locomotor activity are unknown. Decreased hypothalamic nitric oxide formation in cholestasis may contribute to an enhanced behavioural depression in response to IL- 1 in bile duct resected rats. ${ }^{49}{ }^{50}$ The role of cytokines and nitric oxide in the generation of fatigue in cholestatic liver disease requires further investigation as both of these can be modulated for therapeutic advantage.

\section{(4) Peripheral muscle dysfunction}

A recent study suggests contribution of peripheral muscle dysfunction to the fatigue experienced by patients with cholestasis. ${ }^{34}$ Fatigued patients with PBC had markedly accelerated reduction in muscle function on repeat activity compared with both control subjects and non-fatigued patients. ${ }^{34}$ Further, the rate of reduction in muscle function correlated with the severity of fatigue experienced by the patient, suggesting a contribution of the peripheral muscle fatigability to the fatigue experienced by patients. The mechanism underlying peripheral muscle dysfunction is not known. Oxidative stress may play a part as muscle fatigue has been shown to be associated with oxidative stress to myocytes. ${ }^{51}$ Antioxidants prolong the time to development of fatigue in rabbits and humans. ${ }^{52} 53$ Cholestatic liver diseases are associated with oxidative stress mainly due to the pro-oxidant action of retained hydrophobic bile acids, ${ }^{5455}$ while antioxidants protect against this pro-oxidant action..$^{56-58}$ Three months of antioxidant therapy improved fatigue 


\section{Box 2: Treatment of fatigue}

- Ursodeoxycholic acid: no relief.

- Antioxidants: more studies required.

- Serotonin antagonists: experimental.

- Interleukin-1 ra: experimental.

- Liver transplant: last resort.

\section{Box 3: Learning points}

- Fatigue is a major symptom in cholestatic liver diseases present in $60 \%-85 \%$ of patients with primary biliary cirrhosis.

- It is worst or one of the worst symptoms in $50 \%$ of patients.

- It has an adverse effect on quality of life.

- Fatigue severity does not correlate with severity of underlying liver disease

- Pathogenesis of fatigue is still obscure.

- At present there is no treatment for fatigue.

considerably in patients with $\mathrm{PBC}$, suggesting a role of oxidative stress in the development of fatigue. ${ }^{59}$

\section{TREATMENT OF FATIGUE IN CHOLESTATIC LIVER DISEASE}

Currently no therapy is effective in relieving the symptoms of fatigue in patients with cholestatic liver disease. UDCA is considered the treatment of choice for PBC at present. It reduces the pace of disease progression and delays time to transplantation. ${ }^{60}$ It, however, has no effect on the accompanying fatigue. ${ }^{11-13}$ Liver transplant also does not help much in relief of fatigue. Fatigue remains the most distressing symptom even one year after liver transplantation, though its intensity is reduced..$^{14}$

Other known causes of fatigue such as anaemia, electrolyte imbalance, renal failure, hypothyroidism, or side effects of drugs should be looked for and treated. Avoidance of stress and promotion of healthy lifestyle including adequate sleep, regular exercise, and alcohol and caffeine restriction may help. ${ }^{61}{ }^{62}$ Antidepressants may relieve fatigue partially in depressed patients. ${ }^{61}$

It is important to understand the pathogenesis of fatigue in cholestatic liver disease before any therapeutic breakthrough can be achieved. The role of serotoninergic neurotransmission, IL-l and nitric oxide in the pathogenesis of fatigue, as suggested in rat experiments, may provide a rationale for treatment in future as these can be modulated using specific antagonists. In this respect, the reports of reversal of fatigue in cholestatic rats using $5-\mathrm{HT}_{1 \mathrm{~A}}$ receptor antagonist $\mathrm{t}^{33}$ and similarly, reversal of sickness behaviour using IL-1ra ${ }^{29}$ are encouraging.

Antioxidants were found to reduce fatigue in a pilot study ${ }^{59}$ However, the role of antioxidants in amelioration of fatigue needs further evaluation by larger controlled trials.

\section{Authors' affiliations}

D Kumar, R K Tandon, Department of Gastroenterology, All India Institute of Medical Sciences, New Delhi, India

\section{REFERENCES}

1 Witt-Sullivan H, Heathcote EJL, Cauch-Dudek K, et al. The demography of primary biliary cirrhosis in Ontario, Canada. Hepatology 1990:12:98-105.

2 Cauch-Dudek K, Abbey S, Stewart DE, et al. Fatigue in primary biliary cirrhosis. Gut 1998;43:705-10

3 Barofsky I, Legro MW. Definition and measurement of fatigue: approaches in data collection. Rev Infect Dis 1991;13:S94-S97.

4 Metcalf J, Mitchison H, Palmer J, et al. Natural history of early biliary cirrhosis. Lancet 1996;348: 1399-402.
5 Poupon RE, Lindor KD, Cauch-Dudek K, et al. Combined analysis of randomized controlled trials of ursodeoxycholic acid in primary biliary cirrhosis. Gastroenterology 1997;113:884-90.

6 Lindor KD, Poupon RE, Poupon R, et al. Ursodeoxycholic acid for primary biliary cirrhosis. Lancet 2000;355:657-8.

7 Lindor KD, Therneau TM, Jorgensen R, et al. Effects of ursodeoxycholic acid on survival in patients with primary biliary cirrhosis. Gastroenterology 1996;1 10:1515-8.

8 Poupon RE, Bonnand AM, Chretien Y, et al, The UDCA-PBC study group. Ten year survival in ursodeoxycholic acid treated patients with primary biliary cirrhosis. Hepatology 1999;29:1668-71.

9 Goulis J, Leandro G, Burroughs AK. Randomised controlled trials of ursodeoxycholic acid therapy for primary biliary cirrhosis: a meta analysis. Lancet 1999;354:1053-60.

10 Huet PM, Deslauriers J, Tran A, et al. Impact of fatigue on the quality of life of patients with primary biliary cirrhosis. Am J Gastroenterol 2000;95:760-7

11 Vuoristo $M$, Farkilla M, Kamonen AL, et al. A placebo controlled trial of primary biliary cirrhosis with colchicines and ursodeoxycholic acid. Gastroenterology 1995;108:1470-8.

12 Lindor KD, Dickson RE, Baldus WP, et al. Ursodeoxycholic acid in the treatment of primary biliary cirrhosis. Gastroenterology 1994:106:1284-90

13 Heathcote EJ, Cauch-Dudek K, Walker V, et al. The Canadian multicenter double blind randomized controlled trial of ursodeoxycholic acid in primary biliary cirrhosis. Hepatology 1994;19:1 149-56.

14 Gross CR, Malinchoc M, Kim WR, et al. Quality of life before and after liver transplantation for cholestatic liver disease. Hepatology 1999:29:356-64

15 Katsinelos P, Vasiliadis T, Xiarchos P, et al. Ursodeoxycholic acid (UDCA) for the treatment of amoxycillin-clavulanate potassium (Augmentin)-induced intra-hepatic cholestasis: report of two cases. Eur J Gastroenterol Hepatol 2000;1 2:365-8.

16 Schwartz JE, Krupp LB. The measurement of fatigue: a new instrument. J Psychosom Res 1993;37:753-62.

17 Fisk J, Ritvo P, Ross L, et al. Measuring the functional impact of fatigue: initial validation of the fatigue impact scale. Clin Infect Dis 1994; 18:S79-S83.

18 Prince MI, James OF, Holland NP, et al. Validation of a fatigue impact score in primary biliary cirrhosis: towards a standard for clinical and trial use. J Hepatol 2000;32:368-73

19 Kent S, Bluthe R-M, Kelley KW, et al. Sickness behaviour as a new target for drug development. Trends Pharmacol Sci 1992;13:24-8.

20 Hart BL. Biological basis of the behaviour of sick animals. Neurosci Biobehav Rev 1988;12:123-37.

21 Koob GF, Heinrichs SC, Pich EM, et al. The role of corticotropin releasing factor in behavioural responses to stress. Ciba Found Symp 1993; 172:277-95.

22 Sternberg EM, Glowa JR, Smith MA, et al. Corticotropin releasing harmone related behavioural and neuroendocrine responses to stress in Lewis and Fischer rats. Brain Res 1992;570:54-60.

23 Bearn J, Wessely S. Neurobiological aspects of the chronic fatigue syndrome. Eur J Clin Invest 1994:24:79-90.

24 Bakheit AMO, Behan PO, Dinan TG, et al. Possible upregulation of hypothalamic 5-hydroxytryptamine receptors in patients with postviral fatigue syndrome. BM 1992;304:1010-2.

25 Bergasa NV, Jones EA. The pruritus of cholestasis. Potential pathogenic and therapeutic implications of opioids. Gastroenterology 1995; 108:1582-8.

26 Schworer H, Hartmann H, Ramadori G. Relief of chplestaric pruritus by a novel class of drugs: 5 -hydroxytryptamine type 3 (5HT3) receptor antagonists: effectiveness of ondansetron. Pain 1995;61:33-7.

27 Otterness IG, Seymour PA, Golden HW, et al. The effects of continuous administration of murin interleukin-la in the rat. Physiol Behav 1988:43:797-804

28 Segreti J, Gheusi G, Dantzer R, et al. Defect in interleukin-1 $\beta$ secretion prevents sickness behaviour in $\mathrm{C} 3 \mathrm{H} / \mathrm{HeJ}$ mice. Physiol Behav 1997;61:873-8.

29 Kent S, Bluthe RM, Dantzer R, et al. Different receptor mechanisms mediate the pyrogenic and behavioral effects of interleukin 1. Proc Natl Acad Sci U S A 1992;89:9117-20.

30 Swain MG, Patchev V, Vergalla J, et al. Suppression of hypothalamic-pituitary-adrenal axis responsiveness to stress in a rat model of acute cholestasis. J Clin Invest 1993;91:1903-8.

31 Swain MG, Maric M. Defective corticotropin releasing hormone mediated neuroendocrine and behavioral responses in cholestatic rats: implications for cholestatic liver disease-related sickness behaviors. Hepatology 1995;22:1560-4.

32 Swain MG, Maric M. Improvement in cholestasis associated fatigue with a serotonin receptor agonist using a novel rat model of fatigue assessment. Hepatology 1997:25:291-4.

33 Swain MG, Beck P, Rioux K, et al. Augmented interleukin-1 $\beta$-induced depression of locomotor activity in cholestatic rats. Hepatology 1998;28:1561-5

34 Goldblatt J, James OF, Jones DE. Grip strength and subjective fatigue in patients with primary biliary cirrhosis. JAMA 2001;285:2196-7.

35 Dunn AJ, Berridge CW. Physiological and behavioural responses to corticotropin-releasing factor administration: is CRF a mediator of anxiety or stress responses? Brain Res Rev 1990;15:71-100.

36 Whimbey AE, Denenberg VH. Two independent behavioural dimensions in open field performance. J Comp Physiol Psychol 1967;3:500-4

37 Britton DR, Britton KT. A sensitive open field measure of anxiolytic drug activity. Pharmacol Biochem Behav 1981;15:577-82. 
38 Bonaz B, Tache Y. Water avoidance stress induced c-fos expression in the rat brain and stimulation of faecal output: role of corticotropin-releasing factor. Brain Res 1994;641:21-8.

39 Bailey SP, Davis JM, Ahlborn EN. Neuroendocrine and substrate responses to altered brain 5-HT activity during prolonged exercise to fatigue. J Appl Physiol 1993;74:3006-12.

40 Wilson WM, Maughan RJ. Evidence for a possible role of 5 -hydroxytryptamine in the genesis of fatigue in man: administration of paroxetine, a 5-HT re-uptake inhibitor, reduces the capacity to perform prolonged exercise. Exp Physiol 1992:77:921-4.

41 Schworer H, Hartmann H, Ramadori G. Relief of cholestatic pruritus by a novel class of drugs: 5-hydroxytryptamine type 3 (5-HT3) receptor antagonists: effectiveness of ondansetron. Pain 1995;61:33-7.

42 Spadaro F, Dunn AJ. Intracerebroventricular administration of interleukin-1 to mice alters investigation of stimuli in a novel environment. Brain Behav Immun 1990;4:308-22.

43 Uehara A, Sekiya C, Takasugi Y, et al. Anorexia induced by interleukin-1: involvement of corticotropin-releasing hormone. Am J Physiol 1989;257:R613-7.

44 Linthorst AC, Flackskamm C, Muller-Preuss P, et al. Effect of bacterial endotoxin and interleukin-1 beta on hippocampal serotoninergic neurotransmission, behavioral activity, and free corticosterone levels: an in vivo microdialysis study. J Neurosci 1995;15:2920-34.

45 Swain MG, Beck P, Rioux K, et al. Augmented interleukin-1 beta induced depression of locomotor activity in cholestatic rats. Hepatology 1998;28:1561-5.

46 Hagan P, Poole S, Bristow AE. Endotoxin stimulated production of rat hypothalamic interleukin-1 beta in vivo and in vitro, measured by specific immunoradiometric assay. J Mol Endocrinol 1993;11:31-6.

47 Van-Dam AM, Baver J, Tilders FJ, et al. Endotoxin induced appearance of immunoreactive interleukin-1 beta in ramified microglia in rat brain: a light and microscopic study. Neuroscience 1995;65:815-26.

48 Minami M, Kuraishi Y, Hamaguchi T, et al. Immobilization stress induces interleukin-1 beta-mRNA in the rat hypothalamus. Neurosci Lett $1991 ; 123: 254-6$.
49 Bluthe RM, Sparber S, Dantzer R. Modulation of the behavioural effect of interleukin-1 in mice by nitric oxide. Neuroreport 1991;3:207-9.

50 Swain MG, LeT, Tigley AW, et al. Hypothalamic nitric oxide synthase is depressed in cholestatic rats. Am J Physiol 1997;272:G1034-40.

51 Sumida S, Tanaka K, Kitao H, et al. Exercise induced lipid peroxidation and leakage of enzymes before and after vitamin E supplementation. Int J Biochem 1989;21:835-8

52 Khawli FA, Reid MB. N-acetylcysteine depresses contractile function and inhibits fatigue of diaphragm in vitro. J Appl Physiol 1994:77:317-24.

53 Reid MB, Stokie DS, Koch SM, et al. N-acetylcysteine inhibits muscle fatigue in humans. J Clin Invest 1994;94:2468-74.

54 Sokol RJ, Devereaux M, Khandawala RA. Effect of dietary lipid and vitamin $E$ on mitochondrial lipid peroxidation and heptic injury in the bile duct ligated rat. J Lipid Res 1991;32:1349-57.

55 Paradis V, Kollinger $M$, Fabre $M$, et al. In situ detection of lipid peroxidation by products in chronic liver disease. Hepatology 1997:26:135-42.

56 Sokol RJ, Winkelhofer A, Roob BM, et al. Generation of hydroperoxides in isolated rat hepatocytes and hepatic mitochondria exposed to hydrophobic bile acids. Gastroenterology 1995;109:1249-56.

57 Sokol RJ, McKim JM, Goff MC, et al. Vitamin E reduces oxidant injury to mitochondria and the hepatotoxicity of taurochenodeoxycholic acid in the rat. Gastroenterology 1998;114:164-74.

58 Krahenbuhl S, Talos C, Lauterberg BH, et al. Reduced antioxidative capacity in liver mitochondria from bile duct ligated rats. Hepatology 1995;22:607-12.

59 Watson JP, Jones DE, James OF, et al. Oral antioxidant therapy for the treatment of primary biliary cirrhosis: a pilot study. J Gastroenterol Hepatol 1999; 14:1034-40.

60 Kumar D, Tandon RK. Use of ursodeoxycholic acid in liver diseases. J Gastroenterol Hepatol 2001;16:3-14.

61 Swain MG. Fatigue in chronic disease. Clin Sci 2000;99:1-8.

62 Bergasa NV, Mehlman JK, Jones EA. Pruritus and fatigue in primary biliary cirrhosis. Baillieres' Clin Gastroenterol 2000;14:643-55.

\section{Call for peer reviewers}

Clinical Evidence is a regularly updated evidence based journal available world wide both as a paper version and on the internet. Clinical Evidence urgently needs to recruit a number of new contributors. Contributors are health care professionals or epidemiologists with experience in evidence based medicine and the ability to write in a concise and structured way.

Clinical Evidence needs to recruit a number of new peer reviewers. Peer reviewers are health care professionals or epidemiologists with experience in evidence based medicine. As a peer reviewer you would be asked for your views on the clinical relevance, validity and accessibility of specific topics within the journal, and their usefulness to the intended audience (international generalists and health care professionals, possibly with limited statistical knowledge). Topics are usually 2000-3000 words in length and we would ask you to review between 2-5 topics per year. The peer review process takes place throughout the year, and our turnaround time for each review is ideally 10-14 days.

If you are interested in becoming a peer reviewer for Clinical Evidence, please complete the peer review questionnaire at www.clinicalevidence.com or contact Polly Brown (pbrown@bmigroup.com). 